\title{
Does global change matter? The case of industries in the Upper Danube catchment area
}

\author{
M. Egerer \& M. Zimmer \\ Ifo Institute for Economic Research at the University of Munich, \\ Germany
}

\begin{abstract}
The focus of this paper lies in a fundamental discussion on sustainable water-use in industrial production processes in humid developed regions. Representative for such a region, it is based on the industries in the Upper Danube catchment area. It seeks to point out water-related problems the companies in the catchment area are currently faced with and potential difficulties that could occur in the future, with a special focus on global change. Furthermore, we point out how companies try to cope with these problems. The necessary information was collected in a three-stage process. This process included firstly a questionnaire campaign. About 1,000 questionnaires were sent to relevant companies; about 160 replied. In the second stage telephone interviews were made with companies' representatives who had indicated their willingness to be interviewed in the questionnaire. Thirdly we visited eight companies personally. The main results of this process are presented in this paper.
\end{abstract}

Keywords: industrial water use, global change, water shortage, case study.

\section{Introduction}

A human being can easily reach its natural lifespan without oil but can only survive a few days without water. Water is the most important natural resource which is both restrictable in access and indispensable to sustain social, economic and ecological human needs. The functioning of material cycles strongly depends on a sustainable usage of the water resources. Efficiency implies that social, ecological and economic functions compete with each other and have to 
be balanced and limited in their scale to avoid water scarcity or an overuse of the resource.

While in arid regions water scarcity is a well-discussed issue, it has just recently become the focus of an increased awareness in the rather humid regions of our planet. Especially the exceptionally dry and hot weather conditions in 2003 led to an increased sensitivity to this topic in Germany. In some regions water threatened to become scarce; a few communities in southeast Bavaria even had to be supplied by trucks for some days or weeks. But scarcity is more broadly defined than just lack of the resource. It is rather a lack in the usable amount of the resource, and this scarcity can be caused by an excess as well. Recall the poisoning of drinking water that can be caused by a flood.

Water demand of different users in Germany and Austria

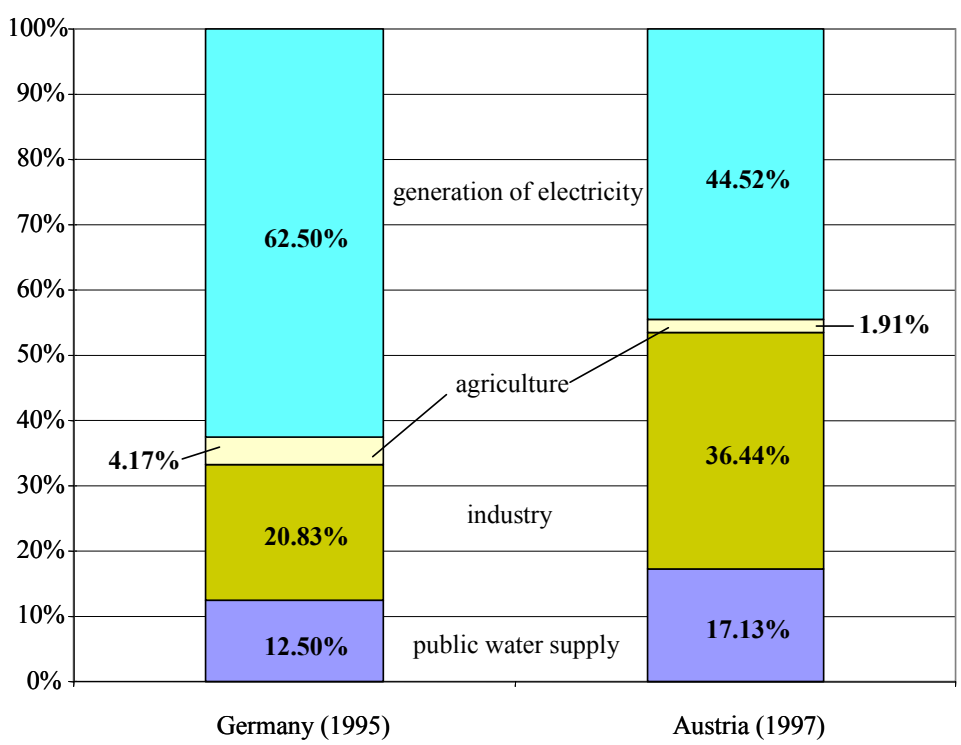

Figure 1: Water use in Germany and Austria (Statistik Austria [11], Umweltbundes-amt [11]).

This work centres on the sustainable use of water in its economic function, and in this function it spotlights the issues and problems expressed by the prime use of the resource: industrial production and power generation. (For a comparison between different uses in Germany and Austria, see Figure 1.) As a regional focus the humid Upper Danube catchment area has been exemplarily selected. This region primarily includes parts of Bavaria and BadenWurttemberg in Germany and Tyrol in Austria.

The major industrial water users are typically self-supplied. In Bavaria and Baden-Wurttemberg this proportion adds up to $95.4 \%$ and $99.1 \%$ of industrial water demand (Federal Statistical Office Germany [4]). The most obvious use for water in the industrial production is its use as an input factor, which includes 
cleaning and transport of intermediate goods. Less apparently but as important is its function as cooling fluid. Thirdly water is used for personal sanitation. The amount of water withdrawn and the amount effectively employed typically differ through re-use, e.g. process water is used for cooling later on, or circulation-use as in a closed cooling cycle. In Bavaria and Baden-Wurttemberg the average utilization coefficient for all branches is 3.8 and 2.4, resp. (Federal Statistical Office Germany [4]).

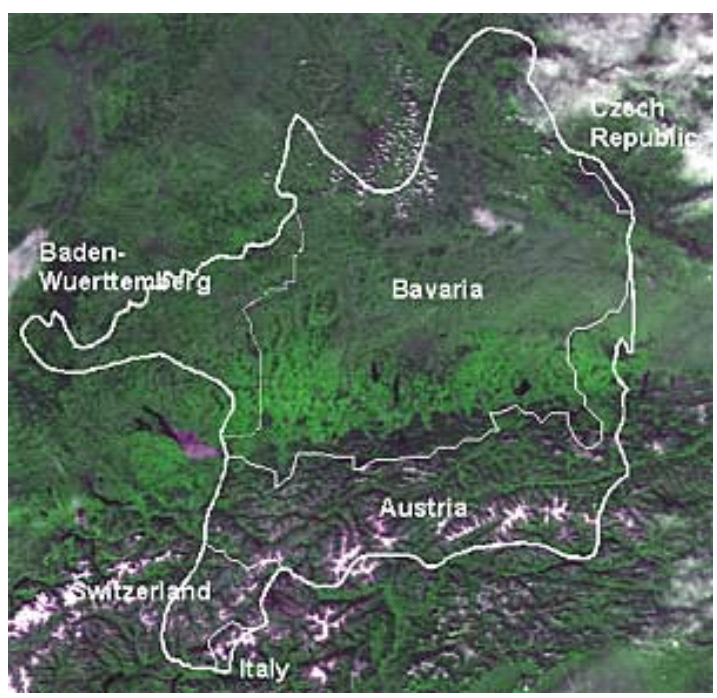

Figure 2: $\quad$ The Upper Danube catchment area.

An introduction to the topic is given in Water Resource Economics by Griffen [8], and a collection of significant papers about industrial water use can be found in Renzetti [9] or in Gispert [7], who focuses on empirical literature of estimating price elasticities. Our study points out the current and possible future problems for industrial water users in the humid Upper Danube catchment area, caused by global change. The results presented here are not meant to be representative for water intensive industries but are intended to enrich the academic discussion with the important aspects of industrial water use. While some of the results might seem obvious, the specific problems of humid regions might be new in the discussion on industrial water use.

Chapter two of the paper introduces the Upper Danube catchment area. Chapter three describes the employed methodology of the three-step inquiry approach to gather the relevant information about current and future problems of industrial water use. Chapter four shows the most important results, subdivided into five aspects: water contingents, water withdrawal and water shortage, water quality, investments in water-saving technologies and possibilities to save water in the production process. The paper concludes with a summary and a conclusion. 


\section{The Upper Danube catchment}

The Upper Danube catchment basin is localized in humid latitudes and covers an area of approximately $80,000 \mathrm{~km}^{2}$ of the Alpine foreland. Administratively it consists mainly of parts of Bavaria but also includes smaller parts of BadenWurttemberg, Austria, and Grisons in Switzerland (Figure 2). The issues in this work provide a base that has to be considered in developing tools to evaluate management alternatives concerning water management and sustainable development. It also helps to set the socio-economic and climatic boundary conditions for simulating future scenarios.

\section{Methodology}

Conducting research on the sustainability of industrial water use will ideally be based on a panel of microeconomic data, if available, that contains each single site in the observed area. These data may provide information about each site's current economic indicators, water demands, water usage and pollution discharges for the regional sample provided mainly by the German Forschungsdatenzentrum [6]. Nevertheless they still lack reasons, potentials, risks, difficulties and expectations. What has led to the currently employed water circulation technologies? What are the water related problems the companies are faced with and what are the difficulties they expect to face in the future? What will be the effects of global change and changes in the institutional framework? And how will the single company react to all of these changes? This study tries to build a bridge between academics discussing theoretical approaches and managers and engineers expressing their views and concerns, thus trying to connect a schematized reality to the factual conditions.

The necessary information about current and future water-related aspects has been collected in a three-step inquiry process. First, after identifying the waterintensive industrial producers and power plants, a questionnaire campaign was conducted. In the observed catchment area only the chemical industry, paper manufacturing and, most importantly, thermal power plants, were identified as relevant (Federal Ministry for Agriculture, Forestry, Environment and Water Management [3]; Federal Statistical Office Germany [4]). In a second stage we conducted extensive telephone interviews with twenty firms-representatives. These were selected out of the 160 replies to approximately one thousand questionnaires sent. In the last stage, six of these company representatives were visited personally. They were either environmental representatives of the companies or engineers responsible for the production. The following part presents the main results of the telephone and personal interviews.

\section{Results}

The interviews covered companies of the chemical, the paper and the cement industry manufacturing as well as thermal and hydroelectric power plants. The production sites visited covered four production sites in different sectors of the 
chemical industry, one cement works and three paper mills, which were part of a common group.

\subsection{Water contingents}

Extraction contingents are allocated by the watershed management authorities to the self-supplying companies. In addition some companies have to pay a fee for each cubic meter water extracted; all companies had to pay a quantity-dependent fee for sewage to the local waste-water treatment plant in case of an indirect discharger and to the local authorities in case of a direct discharger. For the companies we asked, these contingents are usually temporary but commonly allocated for long time spans of ten to fifteen years or sometimes even longer. The certificates can, apart from regulating yearly extraction, also limit monthly, daily or even hourly extraction. In practice the companies mainly monitor their extraction themselves and it is unlikely that any sanctions will be imposed if a limit other than the yearly one is exceeded. Even the excess of the yearly limit usually does not immediately lead to disciplinary measures if the incidence is temporary and the company can justify the causes.

Additionally the contingents may also regulate the temperature difference of the extracted surface water and the re-discharged wastewater, as well as its maximum absolute temperature and its contaminant loads. The maximum inflow temperature varied between 18 and 30 degrees Celsius. Usually a mixed system of periodical checks and self-control was used. Depending on a good relationship to the public authorities, companies often take precautionary measures to reduce water consumption and pollution. Contingents and quantity-dependent fees were unanimously regarded as the best regulative solution to allocate water. In addition some representatives highly valued the close connection to the regional authorities that grant the contingents and worried about a higher anonymity and a national orientation of alternative solution like tradable contingents would imply.

\subsection{Water withdrawal and water shortage}

For the visited sites, process and cooling water were usually self-supplied. In addition regional water suppliers provide small quantities for sanitary facilities. Water contingents reached up to 15 million cubic meters annually. Exploration typically varied from $20 \%$ to $50 \%$ up to slightly above $100 \%$ in one case in the extremely hot summer of 2003. In the industrial sector, water withdrawal has declined in recent years in Germany and Austria (Figure 4). Despite the hot and dry summer of 2003 companies do not expect a future quantity problem. Nevertheless the following two cases of quantitative problems were encountered during our investigations.

One of the observed sites relies on a flow temperature of exactly 12 degrees Celsius, reached by mixing the warm outflow with the freshwater inflow. For the specific well, groundwater temperature reaches its peak in December, usually averaging 10.6 degrees. The very wet summer of 2004 caused the groundwater temperature to rise in December to 11.5 degrees, which almost tripled the demand for fresh water. 


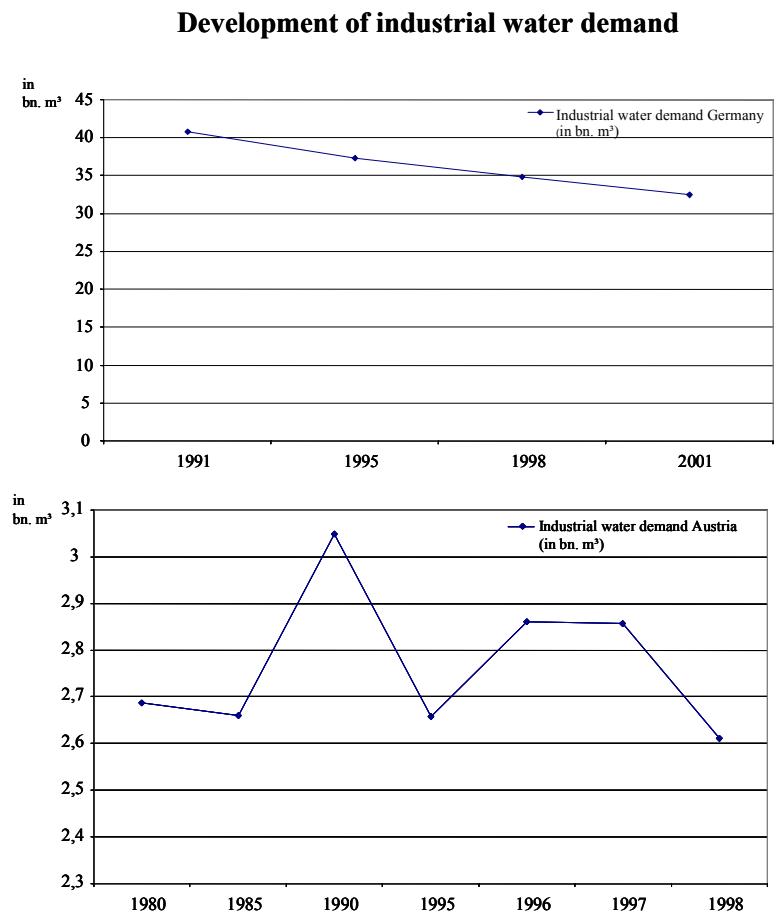

Figure 3: Development of Industrial Water Use in Germany and Austria (Federal Statistical Office Germany [5]; Statistik Austria [11]).

Not surprisingly the second case affected by water shortage was a hydroelectric power plant. More surprisingly a lack of usable water for power production is caused rather by too much than by too little water. Being built in positions with a relatively certain supply of water, low water levels are more likely to be the result of cold temperatures in which precipitation falls as snow. Heat may even help the water supply by accelerating the snow-melt. The most likely cause for a lack of usable water is extreme rainfall or a flood, which pollute the water with lots of particles and sediments. These force the power plant to operate at low capacity to prevent harm to the facilities.

\subsection{Water quality}

Due to the sufficient quality, extracted water is usually only filtered mechanically. Water softener, anti-corrosives and algaecides and demineralization are used to protect the cooling systems. If water quality is reduced drastically, it is in most cases through heavy rainfall and flooding. Water quality is expected to stay constantly good in the future. 


\subsection{Investments in water-saving technologies}

If asked for the dominant reasons to investment in environment-friendly, watersaving technologies, all interview partners agreed on possible cost savings followed by legal obligations. Cost advantages come mainly from saved waste water charges but also from saved fresh water charges. The short planning horizon of two or three years in publicly owned firms was stated to be the main reason not to realize environmental investments with slow amortization. Most representatives of these water-intensive industries specified the total costs of water, including wastewater, to be less than one percent, expecting only a slight increase in the short as well as in the long run.

Since thermal power production is one of the most water-intensive processes, a substantial increase in water costs will cause a rise in energy prices. Therefore this indirect cost effect might be higher than the direct one and since many production sites produce part of their energy themselves, they will increase their own energy production and therewith their water demand.

\subsection{Possibilities to save water in the production process}

The technological options to reduce freshwater demand can be grouped in the three basic categories: process optimization, improvement of the utilization factor and substitution of water by other factors.

Common examples of process optimization include improved monitoring and increased awareness and training of the engineering staff or improvement of the effectiveness of water in the existent production process by installing more efficient heat exchangers or constructing cooling towers. In one case only the improved monitoring led to a reduction of $70 \%$ simply by load-dependent regulation of the cooling system.

Typical approaches for multiple or cycle-use of water mainly include recovery and cleaning of polluted process water and its re-use in further production steps as well as the use of heated cooling water for the same or other purposes like the site's heating system. Typical recovery methods employed include condensation of steam and reverse osmosis. But reducing extraction might not always be desired. To protect the industrial area around it, at one of the visited production sites the extraction would have to continue even if the plant is closed down to prevent the area from becoming swampy again.

As an example of a substitute, compressed air cooling could be used instead of water cooling. Because of the high installation costs this is generally not an option for existing facilities.

\section{Conclusion}

In this paper we tried to analyze current and future water-related problems for the industries in the Upper Danube catchment area and show how they cope with them. Do the companies' representatives believe that they can use their water resources sustainably? Do they expect water to become scarce in quantity or 
quality, especially due to the effects of global change? And how would they react to that?

In the observed region companies do not expect that water will become scarce as a factor of production. A short planning horizon, caused by the need to generate high rates of return for investments, leads companies to react to problems instead of taking preventive measures. Large potentials in the improvement of the utilisation factor are still idle, and thus substantial reductions in the fresh-water demand are possible but economically unattractive for the investors. Nevertheless even in the humid region of the Upper Danube the increased awareness of possible future climate scenarios has led to a change in thinking and decision-making of companies, institutions and authorities. Opportunities to insure the sustainable use of water resources are already often realized in new or re-investments and existing facilities are optimized due to legal obligations or economic incentives. The majority of firms are by now indirectly affected through global change because of rising energy prices in hot periods, destruction and pollution through more and more frequent and severe flooding and high expenditures for flooding protection.

In contrast to the global average, in the observed catchment the most important water users are not the agriculturists, but the electricity suppliers and the industry. Water intense producers are typically self-supplied through ground or river-water. Scarcity in water supply therefore has an especially strong feedback on company-internal power generation or external electricity supply prices. The withdrawal is regulated by detailed contingents which is generally preferred to alternatives like tariffs or tradeable certificates. The cooperation between the private sector and the public supervision authorities is well functioning and even though monitoring is mainly based on self-control regulations are only rarely violated. Water quality, even for river water, is generally sufficient for production processes without any further treatment. The recent climatic changes have led to supply problems in a couple of individual cases. The climatic conditions in the summer of 2003 also led to scarcity in rural areas of Bavaria not well connected to the public water supply infrastructure. But water scarcity in humid regions is usually not characterized by a lack of water supplied. More likely it is caused by pollution. Most common problems are algae in hot periods or suspended particles and oil spill caused by flooding.

The regional specificity of the utilisation of the water resources makes regionspecific research indispensable. Expected problems in the observed area are largely different from those in arid regions. It is essential to consider these peculiarities in further research and in the development of scenarios. By including the issues and challenges the industries, institutions and authorities face at an early stage of the research, the link to the stakeholders can be strengthened. As a consequence the results will meet with broader acceptance and thus generate the impact they often presently lack.

\section{References}

[1] Dupont, Diane P., Renzetti, Steven, The Role of Water in Manufacturing, Environmental and Resource Economics, 18, pp. 411-432, 2001. 
[2] European Environment Agency, Sustainable Use of Europe's Water? State, Prospects and Issues, Copenhagen, 2000.

[3] Federal Ministry for Agriculture, Forestry, Environment and Water Management (Ed.), Umsetzung der Wasserrahmenrichtlinie in Österreich - Wirtschaftliche Analyse der Wassernutzung für den Produktions- und Dienstleistungssektor, 2003.

[4] Federal Statistical Office Germany, Umwelt - Wasserversorgung und Abwasserbeseitigung in der Industrie, Fachserie 19, Reihe 2.2, Wiesbaden, 2003.

[5] Federal Statistical Office Germany, Umweltnutzung und Wirtschaft Tabellen (Band 1) zu den Umweltökonomischen Gesamtrechnungen 2005, Wiesbaden, 2005.

[6] Forschungsdatenzentrum der Statistischen Landesämter (Ed.), Amtliche Mikrodaten für die wissenschaftliche Forschung: Aktuelles Datenangebot, Düsseldorf, 2006.

[7] Gispert, Cristina, The Economic Analysis of Industrial Water Demand: a review, Environment an Planning C: Government and Policy, 22, pp. 15-30, 2004.

[8] Griffin, Ronald C., Water Resource Economics: The Analysis of Scarcity, Policies and Projects, The MIT Press: Cambridge (Massachusetts), London (England), 2006.

[9] Renzetti, Steven, The Economics of Industrial Water Use, Edward Elgar: Cheltenham (UK) and Northampton (Massachusetts, USA), 2002.

[10] Reynaud, Arnaud, An Econometric Estimation of Industrial Water Demand in France, Environmental and Resource Economics, 25, pp. 213-232, 2003.

[11] Statistik Austria, Regionale Wasser-, Abwasser, und Abfalldaten 19801999, Statistische Nachrichten, 5, pp. 374-380, 2002.

[12] Umweltbundesamt, Daten zur Umwelt - Der Zustand der Umwelt in Deutschland 2000, CD-Rom, Berlin 2000. 